\title{
A auditoria governamental como instrumento de promoção da transparência
} The government auditing as a tool for promoting transparency Marcus Vinicius de Azevedo Braga'

\section{Resumo:}

Este artigo analisa as possibilidades e os ganhos na utilização da auditoria governamental como ferramenta de avaliação e melhoria gerencial dos processos de transparência da gestão pública. Discutindo uma questão central acerca das formas de ajuda que a auditoria pode dar à transparência na gestão pública, o trabalho mostra, com base em revisão bibliográfica, as possibilidades e dificuldades encontradas neste processo.

Palavras-chave: Auditoria; Transparência; Gestão pública.

\begin{abstract}
:
This article examines the possibilities and gains in the use of government auditing as a tool for assessing and improving management of the processes of transparency in public administration. Discussing a central question abouthow can auditing provide transparency in public management, the paper shows, based on literature review, the possibilities and difficulties encountered in this process.
\end{abstract}

Keywords: Auditing; Transparency; Public Administration. 
O presente artigo pretende analisar as possibilidades e os ganhos na utilização da auditoria governamental como ferramenta de avaliação e melhoria gerencial dos processos de transparência da gestão pública.

A abordagem desse tema pode se dar de duas maneiras: a primeira, relacionada à divulgação dos resultados obtidos nos trabalhos de auditoria para o público, como um processo de transparência administrativa, na busca de melhorar a accountability dos órgãos públicos. O segundo, que será a linha temática adotada, procura utilizar a avaliação de processos por meio de auditoria como um auxiliar na aferição da transparência e de produção de recomendações gerenciais, que possibilitem o aprimoramento desse processo na gestão.

Assim, a questão principal desse trabalho é: de que forma a auditoria pode auxiliar na promoção da transparência da gestão pública. As análises para se responder a essa questão central serão oriundas da revisão bibliográfica sobre a matéria, de forma a encontrar nos autores e na legislação, indicações que possibilitem ilustrar o tema e que sirvam de base, dado o escopo limitado, para outros estudos, com interações no campo de pesquisa, de forma a efetuar os aprofundamentos necessários.

\section{O que é transparência?}

O presente tópico busca analisar as definições de transparência na literatura e evidenciar o seu caráter processual e gradativo, o que permite a sua relação com a utilização da auditoria como mecanismo de avaliação.

A transparência é um assunto que se tornou vulgarizado no Brasil por dois fatores históricos, complementares e concomitantes. Os cidadãos demandam, em um contexto democrático, acesso à informação, conhecimento da atuação do Estado e do destino eficiente de seus tributos. Da mesma forma, o fim do regime de exceção do governo militar inaugurou uma nova etapa de aprendizado democrático para a sociedade brasileira, com o fortalecimento das instâncias de participação popular e das atuações sistemáticas e pontuais dos cidadãos e da imprensa, no acompanhamento da coisa pública.
Nessa mesma conjuntura, o avanço tecnológico permitiu que as distâncias se encurtassem e que fosse possível, apenas com o manuseio de teclado, acessar de nossa residência informações diversas sobre pessoas e organizações de todo o mundo, inclusive sobre a atuação do Estado na prestação de serviços públicos.

Essa conjunção de fatores, que catalisou a nossa sociedade da década de 1990 até os dias atuais (2011), materializou-se em normas, procedimentos e movimentos de grupos organizados, dentro e fora dos governos, na construção de uma gestão transparente, em um processo considerado sem volta.

Nesse sentido, pode-se definir transparência da gestão como a atuação do órgão público no sentido de tornar sua conduta cotidiana e os dados dela decorrentes, acessíveis ao público em geral. Essa definição suplanta o conceito de publicidade previsto na Constituição Federal de 1988, pois a publicidade é uma questão passiva, de publicação de determinadas informações como requisito de eficácia. A transparência vai mais além, pois detém-se na garantia de acesso às informações de forma global, não somente àquelas que se deseja apresentar.

A transparência não é um fim em si mesmo, e sim um instrumento auxiliar da população para o acompanhamento da gestão pública (HAGE, 2010). Ela permite que a gestão seja cotejada e avaliada cotidianamente e possui um caráter preventivo, inibindo situações de desvio e malversação de recursos. A falta de transparência na gestão é um forte indicativo de práticas comprometedoras (TREVISAN et alli, 2003). Sem transparência, o controle social caminha às escuras e o próprio governante pode deixar de captar situações indesejáveis na máquina estatal por ele comandada.

O que caracteriza a transparência é o seu aspecto proativo, ou seja, de não existir, via de regra, a necessidade de o cidadão buscar informações via requerimento. Essa postura proativa traz benefícios aos governos, pois melhora o fluxo das informações gerenciais com os cidadãos, contribuindo para a eficiência da ação governamental (DARBISHIRE, 2009), 
fortalecendo a governança e a materialização dos direitos sociais à população.

Esse novo cenário demanda muitos estudos, pois o quadro que temos é o de que:

(...) de fato, com as tecnologias, a sociedade capitalista tornou-se muito mais dinâmica, complexa e, de algum modo, as ações humanas agora estão cercadas de instrumentos reais que possibilitam transparência e controle fiscal e social. Dessa maneira, a presença do Poder Público em quase todas as nossas ações diárias levou a um estreitamento da distância entre 0 cidadão e o Estado, em parte pela transparência, pelos mecanismos de controle e, em outra parte, pelas ações e reações dos sujeitos, ao reinvidicarem como seus os direitos sociais (SILVA, 2010, p. 14).

Entretanto, assim como a globalização carrega em si uma visão mítica de homogeneização, a transparência da gestão e a possibilidade de participação pelo universo digital atrelam a si também esse papel de panacéia solucionadora de todas as questões e contradições inerentes à participação popular nas políticas sociais. Isso se dá pelo fato de vivermos em um momento de mistificação da tecnologia, pois:

0 universalismo é um valor, a globalização e a mundialização são realidade. Internet, rede mundial e global não são, contrariamente ao discurso dominante, a encarnação da referência universalista da comunicação. È simplesmente uma rede técnica que se inscreve numa economia global indiferente às fronteiras. Assim como a CNN não é a "primeira rede de informação mundial", mas simplesmente uma rede americana de notícias, cujo ponto de vista sobre a informação mundial é, acima de tudo, um ponto de vista americano (WOLTON, 2004. p. 69).

Essa disponibilização de dados, bem como os mecanismos de denúncia, também segue essa lógica de poder, convidando-nos muito a observar e a agir pouco. "Observar não é agir. Se não, não haveria diferença entre jornalistas e homens políticos (WOLTON, 2004, p.78)". A dimensão digital da participação não pode desprezar a sua dimensão política, verificando no plano concreto a realidade apresentada no plano virtual.

A tecnologia fetichizada, que suporta os mecanismos de transparência dos órgãos públicos empresta-Ihes o caráter de absolutismo, de acesso irrestrito a tudo e a todos, ignorando o aspecto político envolvido nessa questão. Podemos, dessa forma, dizer que a transparência tem um caráter processual, de construção, que envolve, dentro da teoria clássica da comunicação², um emissor, um receptor, o meio e a mensagem. A transparência é um processo comunicativo.

Cabe registrar que esse receptor nem sempre é identificado, sendo, por vezes, idealizado na construção do público alvo a que se destina. Parafraseando a língua portuguesa, a transparência pode ser uma oração de sujeito oculto ou indeterminado. Mas, esse sujeito destinatário das informações, via de regra existe, em um momento presente ou futuro.

Em termos legais, a alteração na Lei de Responsabilidade Fiscal pela Lei Capiberibe, a Lei Complementar $n^{\circ}$ 131/2009, propiciou o respaldo à transparência na Administração Pública, corrigindo essa lacuna na Carta Magna de 1988, quando tratou, na Seção I do Capítulo IX, da "Transparência da gestão fiscal":

Art. 48.São instrumentos de transparência da gestão fiscal, aos quais será dada ampla divulgação, inclusive em meios eletrônicos de acesso público: os planos, orçamentos e leis de diretrizes orçamentárias; as prestações de contas e o respectivo parecer prévio; o Relatório Resumido da Execução Orçamentária e o Relatório de Gestão Fiscal; e as versões simplificadas desses documentos.

Parágrafo único. A transparência será assegurada também mediante:

I - incentivo à participação popular e realização de audiências públicas, durante os processos de elaboração e discussão dos planos, lei de diretrizes orçamentárias e orçamentos;

I- liberação ao pleno conhecimento e acompanhamento da sociedade, em tempo real, de informações pormenorizadas sobre a execução orçamentária e financeira, em meios eletrônicos de acesso público;

III - adoção de sistema integrado de administração financeira e controle, que atenda a padrão mínimo de qualidade estabelecido pelo Poder Executivo da União e ao disposto no art. 48-A.

Art. 48-A. Para os fins a que se refere 0 inciso $\|$ do parágrafo único do art. 48, os entes da Federação

2 Conforme Sampaio (2001), o modelo criado em 1949 por C.E.Shannon e W.Weaver, concebe a comunicação como uma transmissão de sinais, destacando os conceitos como os de emissor, destinatário, código, sinal, informação, codificação e decodificação, sendo um modelo linear da comunicação, visto como um processo de transporte da informação de um ponto $A$ (o emissor) para um ponto $B$ (o receptor), reduzida a comunicação a uma questão de transporte, no qual as mensagens e significados são tratados como meros sinais a serem identificados e decodificados por um receptor. 
disponibilizarão a qualquer pessoa física ou jurídica 0 acesso a informações referentes a:

I - quanto à despesa: todos os atos praticados pelas unidades gestoras no decorrer da execução da despesa, no momento de sua realização, com a disponibilização mínima dos dados referentes ao número do correspondente processo, ao bem fornecido ou ao serviço prestado, à pessoa física ou jurídica beneficiária do pagamento e, quando for 0 caso, ao procedimento licitatório realizado;

II - quanto à receita: 0 lançamento e o recebimento de toda a receita das unidades gestoras, inclusive referente a recursos extraordinários.

De modo a definir claramente como deve se dar essa transparência, no âmbito governamental, dando concretude a essa questão, ainda que a lei citada careça de parâmetros escalonados, tratando ainda a questão da transparência de forma absoluta.

A transparência, em muitos fóruns de discussão, termina por ser tratada como uma questão imaterial, abstrata. A proposição desse trabalho aponta uma transparência concreta, processual, escalonada e medida; que se apresenta em atitudes determinadas da gestão.

Outro normativo importante para a transparência foi o projeto de lei sobre acesso a informação (PLC n 41/2010). O Governo Federal, na gestão do ex-presidente Luis Inácio Lula da Silva, enviou ao congresso essa proposição de legislação e são dignos de destaque os seguintes trechos desse projeto de Lei que falam diretamente sobre o conceito de transparência:

Art. $3^{\circ}$ Os procedimentos previstos nesta Lei se destinam a assegurar 0 direito fundamental de acesso à informação e devem ser executados em conformidade com os princípios básicos da administração pública e com as seguintes diretrizes:

(..)

IV - fomento ao desenvolvimento da cultura de transparência na administração pública;

Art. $5^{0}$ É dever do Estado garantir o direito de acesso à informação, que será franqueada, mediante procedimentos objetivos e ágeis, de forma transparente, clara e em linguagem de fácil compreensão;

Art. $6^{\circ}$ Cabe aos órgãos e entidades do poder público, observadas as normas e procedimentos específicos aplicáveis, assegurar a:
I - gestão transparente da informação, propiciando amplo acesso a ela e sua divulgação;

Art. 41. 0 Poder Executivo federal designará órgão da administração pública federal responsável:

I - pela promoção de campanha de abrangência nacional de fomento à cultura da transparência na administração pública e conscientização do direito fundamental de acesso à informação;

II - pelo treinamento de agentes públicos no que se refere ao desenvolvimento de práticas relacionadas à transparência na administração pública.

A questão da transparência mais uma vez toma força nos normativos legais, ligada ao aspecto processual, envolvendo, inclusive o fomento à cultura de transparência e o fornecimento de dados em linguagem acessível, sem barreiras técnicas. A transparência, assim, rompe com os liames da questão orçamentária-financeira e passa a incorporar a gestão pública de forma global, envolvendo processos administrativos, a gestão de pessoal e de documentos, a eficácia e a eficiência no atingimento das metas pelos órgãos públicos.

O processo de transparência é uma relação comunicativa entre cidadãos e governos, em que pela clássica teoria da Agência (SLOMSKI, 2009), em uma visão contratualista de Estado, os governos (Agente), por pressão da população (principal), desenvolvem mecanismos de transparência, de modo a mitigar a assimetria informacional entre eles, no processo de delegação de poderes dos cidadãos ao Estado. Explica melhor essa teoria o autor no trecho:

Assim como nas empresas privadas, não é possível monitorar todas as ações dos servidores públicos, pois 0 agente (gestor eleito-prefeito, no município) possui muito mais informações sobre a entidade que dirige do que 0 principal (cidadão). Gera-se, assim, assimetria informacional externa, dado que o cidadão não sabe, com certeza, se 0 agente está maximizando 0 retorno de seu capital na produção de bens e serviços como ele desejaria. Por outro lado, existe também a assimetria interna, haja vista que os servidores públicos, na qualidade de agentes, possuem mais informações sobre suas áreas de atuação do que 0 gestor eleito, na condição de principal. Dessa maneira, o prefeito (Agente de $1^{0}$ estágio) não tem informações suficientes para saber com exatidão se todos os componentes da cadeia agente-principal, nos mais diversos estágios, 
estão seguindo as suas diretrizes, a fim de alcançar a maximização do que ele deseja para prestar contas ao cidadão (principal) (SLOMSKI, 2009, p. 33).

Nessa modelagem está embutida a ideia de que o governo patrocina as avaliações de transparência de seus subordinados, como instrumento de controle e de governança, o que inclui a transparência como elemento de fortalecimento do controle primário da gestão (BRAGA, 2010). A transparência tem várias dimensões: política, social, gerencial e comunicativa.

Esse jogo de busca pela informação e de garantia de atuação do agente em prol do principal, necessita de uma estrutura de transparência concreta, sedimentada, para suavizar as lacunas informacionais, como demanda do jogo democrático em uma sociedade de alto grau tecnológico.

A questão da transparência reclama estudos mais detalhados. Reportagem do Jornal Valor Econômico de 12 de abril de 2011 (BASILE; LYRA, 2011) indica que o Brasil vai liderar uma estratégia internacional de transparência, envolvendo metas a serem cumpridas pelos países signatários. Essas metas, em um total de dezesseis, são definidas a partir de quatro critérios: transparência e democratização financeira; abertura das informações patrimoniais de agentes políticos; acesso a informações pelo público e participação dos cidadãos no acompanhamento e controle das contas do governo. Elas constituem quesitos, eixos de avaliação do grau de transparência daqueles países, definindo de forma objetiva o que é ser um governo aberto ou não.

Da mesma forma, estudos de Cappelli, Leite e Araújo (2010) apresentam que o avanço da transparência no campo normativo demanda modelos que permitem a verificação desse grau de transparência, indicando características que devem estar presentes em uma organização para ser considerada transparente em um determinado nível.

Esses princípios organizam-se, segundo os autores (2010), na forma de estágios, como modelo misto de progressão em linha, mas em que a o estágio avança como um todo, definidos como "degraus de transparência", uma taxonomia desses princípios. Esses degraus são:

\section{- DEGRAU 1 - Acessibilidade}

A transparência é realizada através da capacidade de acesso. Esta capacidade é identificada através da aferição de práticas que efetivam características de portabilidade, disponibilidade e publicidade na organização.

- DEGRAU 2 - Usabilidade

A transparência é realizada através das facilidades de uso. Esta capacidade é identificada através da aferição de práticas que efetivam características de uniformidade, simplicidade, operabilidade, intuitividade, desempenho, adaptabilidade e amigabilidade na organização.

- DEGRAU 3 - Informativo

A transparência é realizada através da qualidade da informação. Esta capacidade é identificada através da aferição de práticas que efetivam características de clareza, completeza, corretude, atualidade, comparabilidade, consistência, integridade e acurácia na organização.

- DEGRAU 4 - Entendimento

A transparência é realizada através do entendimento. Esta capacidade é identificada através da aferição de práticas que efetivam características de concisão, compositividade, divisibilidade, detalhamento e dependência na organização.

- DEGRAU 5 - Auditabilidade

A transparência é realizada através da auditabilidade. Esta capacidade é identificada através da aferição de práticas que efetivam características de validade, controlabilidade, verificabilidade, rastreabilidade e explicação na organização (CAPPELLl; LEITE; ARAÚJO, 2010, p. 101-102).

Esses degraus apresentam um modelo objetivo de quesitos para avaliação do nível de transparência, a exemplo do padrão que existe para os critérios internacionais (BASILE; LYRA, 2011) reportados anteriormente.

O simples fato de tornar os dados disponíveis não faz de uma organização transparente. Esse processo envolve itens, que se relacionam às várias dimensões do ato comunicativo. Existem questões que envolvem o preparo e a qualificação do receptor, a forma de disponibilização dos dados pelo emissor, entre outras. Cabe avançar às classificações das organizações e à promoção da transparência em critérios objetivos. 
Essas questões fundamentais para a materialização da transparência convivem com o mundo concreto da gestão e demandam instrumentos de avaliação sistemática, que permitam ao governante aferir o andamento da transparência como valor na sua gestão e que possibilitem a emissão de recomendações gerenciais para a correção de rumo, no sentido do órgão prosseguir nos estágios de transparência.

\section{A auditoria governamental como promotora da transparência}

Este tópico busca entender a auditoria como um instrumento de avaliação dos processos de transparência. Inicialmente, cabe refletir sobre o conceito de auditoria como um mecanismo que visa à avaliar a gestão pública, emitindo uma opinião e apresentando sugestões de medidas corretivas e preventivas. Pode-se dizer que a auditoria é:

0 conjunto de técnicas que visa avaliar a gestão pública, pelos processos e resultados gerenciais, bem como a aplicação de recursos públicos por entidades de direito público e privado, mediante a confrontação entre uma situação encontrada e determinado critério técnico, operacional ou legal. Trata-se de uma importante técnica de controle em busca de melhor alocação de recursos, não só atuando para corrigir desperdícios, como inibir a impropriedade, a negligência e a omissão e, principalmente, antecipando-se a essas ocorrências, buscando garantir os resultados pretendidos e contribuir para agregar valor ao corpo gerencial (CASTRO, 2009, p. 164).

A auditoria é uma ferramenta do campo público e privado. No âmbito do setor público, recebe de alguns autores a denominação de Auditoria Governamental. Estudo da Associação dos Tribunais de Contas assim a denomina:

AUDITORIA GOVERNAMENTAL: exame objetivo, sistemático e independente, pautado em normas técnicas e profissionais, efetuado em entidades estatais e paraestatais, funções, subfunções, programas, projetos, atividades, operações especiais, ações, áreas, processos, ciclos operacionais, serviços, sistemas e na guarda e aplicação dos recursos, em relação aos aspectos contábeis, orçamentários, financeiros, econômicos, patrimoniais e operacionais, assim como acerca da confiabilidade do sistema de controle interno, por servidores públicos integrantes do quadro permanente das EFs, denominados de profissionais de auditoria governamental, através de levantamentos de informações, análises imparciais, avaliações independentes e apresentação de informações seguras, devidamente consubstanciadas em provas, segundo os critérios de legalidade, legitimidade, economicidade, eficiência, eficácia, efetividade, equidade, ética e preservação do meio ambiente, além de observar a probidade administrativa e a responsabilidade social dos gestores da coisa pública (BRASIL, 2010b, p.11).

Todos esses conceitos ligam-se à avaliação de uma situação concreta - seja um programa de governo, um processo de gestão ou uma organização pública - com a finalidade de avaliar essa situação à luz de parâmetros definidos. A auditoria, que já foi um instrumento voltado exclusivamente à detecção de erros e fraudes, avançou no sentido preventivo e orientador, como um elemento externo de auxílio à gestão, de forma sistemática, documentada e independente, sendo essa informação geradora de um produto a ser encaminhado a um destinatário interessado (BRASIL, 2010).

A obtenção de informações com fins gerenciais pode se dar de várias formas: pesquisas acadêmicas, levantamentos, consultas diretas, etc. Entretanto, o uso de uma ferramenta como a auditoria permite uma análise sistemática, com escopo definido, com procedimentos específicos para consignar todas essas conclusões em um relatório, que diante do diagnóstico da situação encontrada, emite recomendações que serão acompanhadas e discutidas ao longo da gestão, em outros momentos de interação.

A classificação dotada pelas normas de auditoria do TCU (BRASIL, 2010) indica dois tipos de auditoria, de acordo com a sua natureza:

Auditorias de regularidade que objetivam examinar a legalidade e a legitimidade dos atos de gestão dos responsáveis sujeitos à jurisdição do Tribunal, quanto aos aspectos contábil, financeiro, orçamentário e patrimonial. Compõem as auditorias de regularidade as auditorias de conformidade e as auditorias contábeis.

Auditorias operacionais, que objetivam examinar a economicidade, eficiência, eficácia e efetividade de organizações, programas e atividades governamentais, com a finalidade de avaliar o seu desempenho e de promover o aperfeiçoamento da gestão pública (BRASIL, 2010, p.14). 
Apesar da transparência, por força da Lei de Responsabilidade Fiscal (LRF), ser imposição oriunda de uma norma; pelo caráter processual da transparência, pela sua peculiaridade, variando de organização para organização, a presente pesquisa defende que a auditoria operacional, pela sua análise das dimensões de eficácia e de eficiência, poderia servir melhor à análise da transparência das organizações. As auditorias operacionais:

(...) possuem características próprias que as distinguem das auditorias tradicionais. Ao contrário das auditorias de regularidade, que adotam padrões relativamente fixos, as auditorias operacionais, devido à variedade e complexidade das questões tratadas, possuem maior flexibilidade na escolha de temas, objetos de auditoria, métodos de trabalho e forma de comunicar as conclusões de auditoria. Empregam ampla seleção de métodos de avaliação e investigação de diferentes áreas do conhecimento, em especial das ciências sociais (ISSAI 3000/1.2, 2.2, 2004; ISSAI 400/4,21, 2001). Além disso, essa modalidade de auditoria requer do auditor flexibilidade, imaginação e capacidade analítica (ISSAI 3000/1.8, 2004) (BRASIL, 2010a, p. 13).

Pela natureza da atividade de transparência e pela diversidade de soluções que podem surgir na gestão, esse instrumento mostra-se mais adequado à análise demandada, do que a uma auditoria de regularidade, pois:

Nas auditorias de regularidade, as conclusões assumem a forma de opinião concisa e de formato padronizado sobre demonstrativos financeiros e sobre a conformidade das transações com leis e regulamentos, ou sobre temas como a inadequação dos controles internos, atos ilegais ou fraude. Nas auditorias operacionais, o relatório trata da economicidade e da eficiência na aquisição e aplicação dos recursos, assim como da eficácia e da efetividade dos resultados alcançados. Tais relatórios podem variar consideravelmente em escopo e natureza, informando, por exemplo, sobre a adequada aplicação dos recursos, sobre o impacto de políticas e programas e recomendando mudanças destinadas a aperfeiçoar a gestão (ISSAI 400/2-3, 2001)(BRASIL, 2010a, p.13).

Uma abordagem biunívoca, de subsunção, de verificação estrita do cumprimento das normas previstas no campo da transparência, não contribuiu tanto quanto uma análise dos resultados conjugada aos meios para alcançá-los, como se dá pela análise efetuada por uma auditoria operacional. Pretendese com esse estudo, então, propor a Auditoria Operacional como um modelo de auditoria sobre os mecanismos de transparência, entendendose que essa transparência é um componente do Controle Interno Administrativo ou Controle Primário (BRAGA, 2010), como elemento que possibilita um melhor acompanhamento dos processos pelo próprio gestor, conduzindo a eficiência da gestão e o acesso aos direitos sociais.

Definido o instrumento, pode-se enriquecer o estudo fazendo-se uma simulação de como seria uma auditoria operacional em uma escola técnica estadual, por exemplo, apresentando as possibilidades desse instrumento na promoção da transparência.

\section{Exemplificando a utilização da auditoria na promoção da transparência.}

De modo a exemplificar a proposição deste trabalho, vamos tomar uma escola de educação profissional e tecnológica, as chamadas escolas técnicas - no caso uma pertencente à rede estadual de ensino - como exemplo de uma auditoria de natureza operacional, para avaliar a sua transparência, sintetizando o conteúdo abordado até o presente momento.

A auditoria operacional inicia com a seleção do tema, o que, neste caso, já está posto - a transparência. Entretanto, ainda assim se faz necessário identificar, de forma mais própria, o escopo a ser executado, em relação à profundidade das análises requeridas.

Conforme Madrid (2008), os principais critérios para essa delimitação são: o valor agregado à fiscalização (verificar o que tem sido menos auditado); os riscos e incertezas (aquilo que pode afetar os objetivos); e o interesse social do tema (a importância para a comunidade).

No caso da escola técnica, podemos apresentar vários processos que demandam transparência e enquadram-se nos critérios citados: contratação de professores efetivos e temporários; admissão de alunos em projetos de extensão que envolvem a comunidade; 
aquisições e contratações de bens e serviços; escolha das áreas dos diversos cursos técnicos a serem ofertados; e seleção de bolsas de estudo para atividades de pesquisa na comunidade.

Da mesma forma, na análise desse processo, faz-se necessária a identificação dos grupos que são stakeholders ${ }^{3}$ e, ao mesmo tempo, do público-alvo do processo de transparência. Podemos citar em nosso exemplo hipotético os seguintes grupos: a representação da Secretaria Estadual de Educação na região; os alunos; os professores; as famílias; os sindicatos; e o empresariado local.

Dessa relação dos destinatários da informação propiciada pela transparência e pelos processos selecionados, podemos escolher, para fins didáticos, a seleção para bolsas de estudo, por envolver de um modo geral todas as partes interessadas por, ter relevância (remuneração) e pela baixa transparência, por ser um processo interno. Hipoteticamente, a Secretaria Estadual de Educação publicou diversas normas sobre a transparência não só dos processos financeiros, mas também dos processos seletivos e de concessão de bolsas para as suas unidades subordinadas, indicando cinco critérios graduais de avaliação: acesso; utilidade; conteúdo; clareza e auditabilidade. Todos, critérios definidos em parâmetros objetivos que permitem classificar as unidades em $A, B$ e $C$, no que tange a transparência de processos, em um processo educativo.

No prosseguimento da auditoria, faz-se necessário um estudo preliminar da legislação e dos processos envolvidos na concessão de bolsas para pesquisa, identificando os pontos críticos que devem ser objeto de transparência, a luz do público-alvo e dos normativos pertinentes. Para fins do exemplo em comento, identificamos três pontos críticos: a confecção da planilha de pontos do processo seletivo obtidos pelo candidato; os alunos inscritos e seus requisitos; e o resultado final da seleção. Nesse aspecto, conforme Madrid (2008), nos cabe identificar, antes do início da auditoria, os dados tabelados a seguir:

\begin{tabular}{|c|c|}
\hline $\begin{array}{l}\text { Tópico estudo } \\
\text { preliminar }\end{array}$ & Dados coletados \\
\hline $\begin{array}{l}\text { Conhecimento } \\
\text { do processo }\end{array}$ & $\begin{array}{l}\text { Verificou-se que anualmente existem } \\
\text { dois processos seletivos de bolsas para } \\
\text { pesquisa, publicados por edital, abertos } \\
\text { para alunos a Escola Técnica Estadual Xe } \\
\text { de outras da rede pública e particular no } \\
\text { município e da sua região metropolitana. } \\
0 \text { edital prevê, também, a oferta de bolsas } \\
\text { financiadas por empresas privadas, } \\
\text { incluídas no processo de seleção, de } \\
\text { forma a ampliar as pesquisas de } \\
\text { interesse destas, na forma de parceria. } \\
\text { Nunca houve avaliação de transparência } \\
\text { no processo de bolsas. A unidade declara- } \\
\text { se no nível A (maior) de transparência } \\
\text { nesse processo, na sua auto-avaliação do } \\
\text { ano anterior. }\end{array}$ \\
\hline $\begin{array}{l}\text { Análise do } \\
\text { contexto }\end{array}$ & $\begin{array}{l}\text { Denúncias aos órgãos de controle indicam } \\
\text { dificuldade dos envolvidos de tomar } \\
\text { conhecimento das regras e dos critérios } \\
\text { da seleção de bolsas, além de serem } \\
\text { registradas denúncias de favorecimento } \\
\text { de empregados das empresas } \\
\text { financiadoras e de filhos de servidores da } \\
\text { Escola técnica. }\end{array}$ \\
\hline $\begin{array}{l}\text { Grau de } \\
\text { confiabilidade } \\
\text { dos controles } \\
\text { internos }\end{array}$ & $\begin{array}{l}\text { Análise preliminar dos documentos } \\
\text { normativos indica baixa publicidade do } \\
\text { processo de seleção de bolsas. }\end{array}$ \\
\hline $\begin{array}{l}\text { Objetivos da } \\
\text { auditoria }\end{array}$ & $\begin{array}{l}\text { Analisar os processos de transparência da } \\
\text { seleção de alunos para bolsa de pesquisa, } \\
\text { com a indicação de atendimento dos } \\
\text { normativos da Secretaria de Educação } \\
\text { e a proposição de medidas corretivas, } \\
\text { verificando se a escola encontra-se no } \\
\text { nível indicado. }\end{array}$ \\
\hline $\begin{array}{l}\text { Perguntas } \\
\text { básicas da } \\
\text { auditoria }\end{array}$ & $\begin{array}{l}\text { Os pontos críticos do processo tem tido a } \\
\text { transparência necessária? } \\
\text { Apenas a transparência dos pontos } \\
\text { críticos atende à legislação e é capaz de } \\
\text { inibir situações de risco? } \\
\text { Ė possível incrementar outros meios } \\
\text { de transparência ao processo a luz do } \\
\text { público-alvo? } \\
\text { Dentro dos critérios da Secretaria de } \\
\text { Educação, a escola realmente está no } \\
\text { padrão A? }\end{array}$ \\
\hline $\begin{array}{l}\text { Dificuldades na } \\
\text { obtenção dos } \\
\text { dados }\end{array}$ & $\begin{array}{l}\text { Como o processo é conduzido em } \\
\text { todas as etapas pelos professores } \\
\text { que coordenam as linhas de pesquisa, } \\
\text { se prevê a dificuldade de se obter } \\
\text { informações. }\end{array}$ \\
\hline $\begin{array}{l}\text { Critérios de } \\
\text { avaliação da } \\
\text { auditoria }\end{array}$ & $\begin{array}{l}\text { Processos críticos publicados na internet } \\
\text { e em local público, em linguagem clara; } \\
\text { Processos críticos divulgados em local } \\
\text { que permita a sua comparabilidade e } \\
\text { auditabilidade; } \\
\text { Fornecimento de dados úteis e relevantes } \\
\text { pelos processos críticos ao público-alvo, } \\
\text { para que se possa garantir a isonomia e } 0 \\
\text { respeito aos direitos envolvidos. }\end{array}$ \\
\hline
\end{tabular}


Com base nesse levantamento, e com o devido planejamento, a equipe pode efetuar os testes de auditoria em campo, coletando as informações necessárias e utilizando técnicas próprias para cada caso. Concluído os testes, a equipe pode se reunir com a direção da escola para o intercâmbio das informações consignadas, na busca de esclarecimentos adicionais, colhendo manifestações por escrito, se necessário.

Os pontos identificados serão registrados em um relatório, a ser encaminhado para o demandante, a Secretaria Estadual de Educação e para a Escola Técnica, já contendo as recomendações corretivas, de forma a sanar as situações apontadas. Devido a sua natureza operacional, a equipe de auditoria pode apresentar sugestões de melhoria, inclusive aproveitando as boas práticas coletadas de outras unidades em trabalhos dessa natureza.

De forma simples, buscou-se apresentar um exemplo de como a auditoria pode contribuir para o incremento da transparência, com um instrumento de avaliação, proposição e monitoramento. A utilização dessa ferramenta pode contribuir em vários aspectos com a gestão, pois a avaliação e a melhoria da transparência propiciam para a gestão do ente vários avanços, em especial:

A. Controle Social: o controle social pode se converter em um grande auxiliar do gestor, indicando pela denúncia e pelo acompanhamento da gestão as situações impróprias que estão afetando à população;

B. Controle Primário: sendo uma das componentes do controle primário, ou seja, aquele promovido pelo próprio gestor nos seus processos (BRAGA, 2010), a transparência permite verificar o acesso ao fluxo de informações, evitando informações ocultas e tornando claras as ações governamentais desenvolvidas para os públicos de dentro e de fora da organização;

C. Credibilidade da gestão: o titular do poder é o grande interessado pela credibilidade da gestão, pois é ele que colhe o ônus e o bônus de uma boa gestão (BRAGA, 2009). Assim, a transparência é para ele uma ferramenta de incremento dessa credibilidade junto à população, seus eleitores;

D. Atendimento aos normativos: como apresentado nesse trabalho, a tendência dos normativos é exigir de todas as esferas a transparência, o que por si só já demanda dos governantes ações específicas e técnicas nesse sentido;

\section{E. Melhoria do padrão dos serviços} públicos: o modelo de excelência da gestão pública já indica a transparência como um indutor do Controle Social e consequentemente, um promotor da eficácia e da eficiência do Estado. Não se concebe serviços públicos de qualidade sem o acompanhamento da população e a visualização das informações envolvidas;

\section{F. Prevenção à corrupção: autores} clássicos nesse assunto, como Klitgaard (1994), indicam que o monitoramento de possíveis atividades corruptas aumenta a probabilidade de tais atividades serem detectadas e punidas. Mas, esse monitoramento só se faz possível com certa dose de transparência na gestão.

A transparência segue um movimento ascendente na nossa sociedade, face ao período democrático reinante, associado aos avanços da tecnologia, o que conduzirá, naturalmente, aos movimentos sociais que exigirão do Estado, pelos meios que lhe são próprios, o atendimento de demandas por transparência e pelo acesso à informação, cabendo aos governos se precaver com seus mecanismos para atender as reivindicações postas.

\section{Conclusão}

O assunto é extenso e ainda exige discussões e aperfeiçoamentos na prática. Mas, o fato de se dispor de critérios objetivos para se estabelecer níveis de transparência, como processo de gestão, permite que a auditoria seja utilizada como ferramenta de avaliação, controle e recomendação, sobre esses processos na melhoria da gestão.

O artigo procurou, então, abordar de forma introdutória a questão da auditoria de transparência, como elemento da sociedade democrática, que demanda mecanismos de gestão que dêem conta da gradação desse processo de melhoria contínua da transparência.

A auditoria operacional revela-se como instrumento adequado para essas análises, o que permite aos governos formar opinião global sobre os seus mecanismos de transparência, atuando na correção dos processos de forma sistêmica. 
Estudos futuros poderão conjugar as classificações existentes de transparência e os conceitos de auditoria governamental, o que fortalece aspectos procedimentais dessa atuação, conduzindo a processos de manualização e treinamento de pessoal.
Por fim, cabe aos governos enfrentar o desafio da transparência, criando e adaptando ferramentas à sua promoção e avaliação, pois em um contexto do Estado democrático de direito, a transparência é a chave de uma gestão pública de qualidade e do acesso da população aos direitos sociais.

\section{Referências bibliográficas}

BASILE, Juliano; LYRA, Paulo de Tarso. Acordo entre países criará metas para transparência. Jornal Valor Econômico, São Paulo, Caderno Especial. 12.04. 2011.

BRAGA, Marcus Vinicius de Azevedo. O controle primário da gestão pública. Jus Navigandi, Teresina, ano 15, n. 2647,30 set. 2010. Disponível em: <http://jus.uol.com.br/revista/texto/17502>.Acesso em: 04.05.2011.

O lucro político, controle prévio e Hollywood. Disponível em: <http://www.transparenciacapixaba.org.br/artigodetalhe.aspx?verArtigo=0+LUCRO+POLITICO,++CONTROLE+PREVIO+E+HOLLYWOOD>. 2009. Acesso em: 04.05.2011.

BRASIL, Lei Complementar n 101 , de 4 de maio de 2000. Estabelece normas de finanças públicas voltadas para a responsabilidade na gestão fiscal e dá outras providências- Lei de Responsabilidade Fiscal. Disponível em:_http://www.presidencia.gov.br/legislacao/>. Acesso em: 04.05.2011.

Tribunal de Contas da União. Portaria -TCU no 280 de 8.12.2010-Normas de Auditoria do Tribunal de Contas da União, Brasília, 2010.

Tribunal de Contas da União. Manual de Auditoria Operacional. Brasília: TCU, Secretaria de Fiscalização e Avaliação de Programas de Governo (SEPROG), 2010a.

Instituto Rui Barbosa. Normas de Auditoria Governamental-NAGs: Aplicáveis ao Controle Externo. 2010b.

CAPPELLI, Cláudia; LEITE, Julio Cesar Sampaio do Prado; ARAÙJO, Renata Mendes. A importância de um modelo de estágios para avaliar transparência. Revista do Tribunal de Contas do Município do Rio de Janeiro, Rio de Janeiro, RJ, nº 45- Setembro de 2010. Mensal.

CASTRO, Domingos Poubel. Auditoria e Controle Interno na AdministraçãoPública.2. ed. São Paulo: Editora Atlas, 2009.

DARBISHIRE, Helen, ProactiveTransparency: The future of the right to information?,Working Paper prepared for theWorldBank,Access to Information Program. Washington, DC. 2009. Disponível em <http://siteresources.worldbank.org/Extgovacc/Resources.DarbishirePT.pdf>. Acesso em 4.05.2011.

HAGE, Jorge. O governo Lula e o combate a corrupção. 1. ed. São Paulo: Editora Fundação Perseu Abramo, 2010.

KLITGAARD, Robert E. A corrupção sob controle. Tradução, Octávio Alves Velho. Rio de Janeiro: Jorge Zahar Ed., 1994.

MADRID, Alicia García del Castilho Pérez. Módulo III. 1- Fiscalização Operacional: Questões gerais e análise da eficácia. Material de apoio do curso "Fiscalização do setor público, documentação em português- $2^{0}$ Edição", promovido pela Fundação CEDDET, Tribunal de Contas da Espanha e Tribunal de Contas da União. Madrid, 2008.

SAMPAI0, Inês Silvia Vitorino. Conceitos e modelos da comunicação. 2001. Disponível em :〈http://mww.uff.br/mestcii/ines1.htm>, Acesso em 4.05.2011.

SILVA, Maria Abádiada. Notas sobre as noções de tempo e as implicações na educação escolar. In: NASCIMENTO, Claudemiro Godoy do (Org.). Versos e reversos da educação: das políticas às pedagogias alternativas. Goiânia: Editora da PUC de Goiás, 2010. Cap. I, p. 13-30.

SLOMSKI, Valmor. Controladoria e governança na gestão pública-1 Ed.-São Paulo: Atlas, 2009.

TREVISAN, Antoninho Marmo; CHIZZOTTI, Antonio; IANHEZ, João Alberto; CHIZZOTTI, José; VERILLO, Josmar. 0 combate à corrupção nas prefeituras do Brasil. Cotia: Ateliê Editorial, 2003.

WOLTON, Dominique. Pensar a comunicação. Tradução de Zélia Leal Adghirni. Brasília: Editora Universidade de Brasília, 2004. 